\title{
Palliation of a malignant gastrocolic fistula with the use of an atrial septal defect occlusion device
}

A 51-year-old Asian man with metastatic gastric adenocarcinoma presented with a 3-month history of profound diarrhea and weight loss. Laboratory evaluation was significant for anemia and hypokalemia. Computed tomography showed large tumor burden from the gastric antrum with invasion into the ascending colon. Esophagogastroduodenoscopy (EGD) revealed a gastrocolic fistula $30 \mathrm{~mm}$ in diameter within the posterior wall of the gastric antrum, extending for $6 \mathrm{~cm}$ and opening into the ascending colon ( $\bullet$ Fig. 1 ) along with partial obstruction of the pyloric channel. Following discussion of therapeutic options, the patient consented to off-label use of an atrial septal defect (ASD) occlusion device to treat the fistula. Endoscopically, a guidewire was advanced through the fistula tract into the transverse colon. After fluoroscopic sizing with a 34-mm sizing balloon, a 36-mm ASD occlusion device (Amplatzer, St. Jude Medical, St. Paul, Minnesota, USA) was deployed into the tract over the wire alongside the scope. The distal (left atrial) disc was seated within the tract with the proximal (right atrial) disc within the gastric lumen. Injection of contrast revealed little passage of contrast into the fistula. A duodenal stent was then deployed across the pylorus ( $\bullet$ Fig.2). At 6 weeks later the patient had no further diarrhea and his weight had stabilized. Abdominal films showed both devices in stable position.

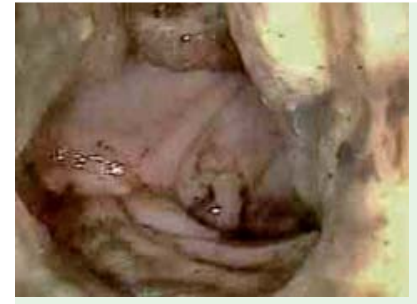

Fig. 1 Antral view of a gastrocolic fistula in a patient with metastatic gastric adenocarcinoma.
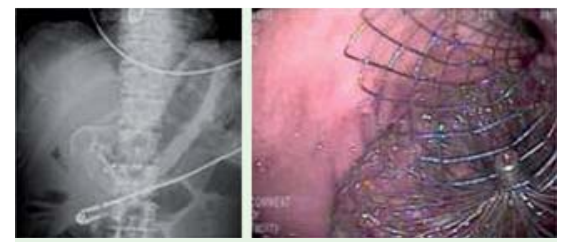

Fig. 2 Fluoroscopic and endoscopic view of the atrial septal defect (ASD) occlusion device and pyloric stent.

Gastrocolic fistulas have been reported as a very rare complication of malignant tumors. In a review of 1500 cases of cancer of the stomach and 3200 cases of carcinoma in the colon, only 11 cases of gastrocolic fistula were found, of which only one case was caused by gastric carcinoma [1]. This case illustrates the novel (but offlabel) use of an ASD closure device combined with a duodenal stent for palliation of a large inoperable malignant gastrocolic fistula and gastric outlet obstruction.
Endoscopy_UCTN_Code_TTT_1AO_2AI

Competing interests: None

\section{Miguel Malespin, Jonathan P. Gaspar, Brian Boulay}

Department of Digestive Diseases and Nutrition, University of Illinois Hospital, Chicago, Illinois, USA

\section{References}

1 Forshaw MJ, Dastur JK, Murali K et al. Longterm survival from gastrocolic fistula secondary to adenocarcinoma of the transverse colon. World J Surg Oncol 2005; 3: 9

\section{Bibliography}

Dol http://dx.doi.org/

10.1055/s-0033-1358931

Endoscopy 2014; 46: E4

(c) Georg Thieme Verlag KG

Stuttgart · New York

ISSN 0013-726X

\section{Corresponding author}

\section{Miguel Malespin, MD}

University of Illinois Hospital

Digestive Diseases and Nutrition

840 South Wood Street,

CSB (MC 716)

Chicago Illinois 60612

United States

Fax: +1-312-996-5103

malespin@uic.edu 